\section{Original} Article

\begin{tabular}{|l|}
\hline Access this article online \\
\hline Website: \\
http://ajobe.journals.ac.za/ \\
\hline DOI: \\
http://dx.doi.org/10.15249/6-1-4 \\
\hline Quick Response Code: \\
\hline
\end{tabular}

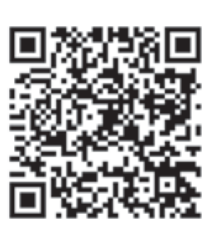

Address for correspondence: Dr. Geoff Goldman, Department of Business Management (Kingsway Campus), University of Johannesburg, PO Box 524, Auckland Park,

2006, Johannesburg, Republic of

South Africa.

E-mail: ggoldman@uj.ac.za

\title{
On the ethical conduct of business organisations: A comparison between South African and polish business management students
}

\author{
Geoff Goldman, Maria Bounds, Piotr Buła', Janusz Fudalinski
}

Departments of Business Management, University of Johannesburg, South Africa, 'Department of International Management at Krakow University of Economics (CUE), Krakow School of Business, ${ }^{2}$ Department of Management Strategy and Development of Organizations, Krakow University of Economics, Poland

\section{ABSTRACT}

This study explores the opinions of Polish and South African management students regarding the ethical conduct exhibited by organisations specific to their respective home countries. Through the use of a survey, primary data were collected via a self-administered questionnaire. Non-probability sampling in the form of a quota sample was employed, and a target of 250 respondents was pursued at a South African and a Polish university respectively. The data were subjected to SPSS. The findings showed that students in South Africa and Poland have little faith in organisations perceived to be conducting business in an ethical fashion. Interesting similarities and differences in Polish and South African opinion were also identified.

Key words: Business ethics, Corporate citizenship, Cultural boundaries, Ethics, Ethical conduct, Stakeholder theory

\section{INTRODUCTION}

Business ethics has long been viewed as something of a contradiction in terms, with an underlying sentiment that it is a glossy veneer on an ocean of deceit and treachery on the part of organisations in the pursuit of net profit (Rossouw and Van Vuuren, 2006). Ethical behaviour of organisations could potentially be insincere and nothing more than just a pretence so that customers (and other stakeholders) may see, and feel at ease with and be reassured that the individual organisation is 'doing the right thing' (Harvey, 2002). Abratt, Bendixen, and Drop (1999) are of the opinion that business people do desire to do what is ethical and right. Harvey (2002) supports this notion, and adds that most organisations participate in legal, honest, right, and fair dealings each day. The motivation for acting ethically is an enhanced organisational reputation, which, in turn, contributes to the firm's performance and shareholder value (Rushton, 2002; Simms, 2006).

According to Clark (2006), however, errors often occur in ethical conduct. This stems from inter alia competitive pressures, resulting in extreme demands on employees to meet unrealistic goals. This, in turn, leads to 'cutting corners' and acting unethically. Also, expediency is often favoured over quality, causing the truth to be stretched. Therefore, the long-term benefits for the organisation are not considered (Harvey, 2002).

Literature (Abratt et al, 1999; Harvey, 2002; Rossouw and Van Vuuren, 2006) suggests that organisations desire to do what is ethical in order to be successful, as it all boils down to the reputation of the organisation and in what light stakeholders perceive the behaviour and intentions of an individual organisation. However, years of training within large organisations has led the authors to different insights as far as the rank-and-file employee is concerned. Inevitably, this has led to a questioning of the bona fides of organisations in this regard.

\section{PURPOSE OF THE STUDY}

From the overview of literature, it is evident that much is being done within organisations to promote ethical behaviour (Harvey 2002; Rossouw andVan Vuuren, 2006; Simms, 
2006). This, however, poses a problem, as seeming ethical and being ethical imply two different things. Being perceived as ethical implies mere compliance, embarking on ethically courses of action to be seen as being ethically correct. It implies something superficial and not sincere to win favour with stakeholders. Being ethical, on the other hand implies sincerity and a heartfelt belief in doing what is morally correct, irrespective of the popularity of the action. The litmus test would thus be the way the ethical behaviour of organisations is perceived by parties external to the business organisations.

Consequently, this study endeavours to answer the following research question:

How do Polish and South African commerce students perceive the ethical conduct of business organisations in their respective home countries?

The choice of these two countries was born out of a curiosity to determine whether these perceptions of ethical behaviour change across cultural boundaries. To answer the stated research question, the primary objective of this study was to measure the opinion of Polish and South African commerce students toward the ethical conduct of business organisations in their home countries.

The benefit of this study lies therein that much literature on business ethics, corporate social investment, and corporate citizenship focuses on what should be done, and has been done, from the organisational point of view, to promote ethical behaviour. However, not much literature exists on peoples' opinions of the ethical behaviour of organisations. This study therefore attempts to shed more light on how students perceive the ethical behaviour of organisations as corporate citizens.

\section{LITERATURE OVERVIEW: FROM ETHICS TO CORPO- RATE CITIZENSHIP}

Ethics can be considered "the science of morality" (Niemanand Bennett, 2006). Some believe that being moral stems from a basic concern about being caught doing something wrong and immoral, while others believe that being moral and ethical is a built-in characteristic of people who are looking out for each other and the continued existence of their species (Rosenstand, 2005). People's definitions of good and evil differ, and only when actions of a legal nature are taken against them, do they realise they acted wrongfully (Pastore, 2003). A guideline that has been employed is the "Golden Rule," according to whichone should treat others as one would like to be treated. This provides adequate grounds on which to base ethical practices that are fair and acceptable (Nieman and Bennett, 2006).
Being ethical therefore involves:

- doing what is honest, right, and good (Harvey, 2002);

- integrity (defined as uncorrupted, and therefore honest (Bradley and Schrom, 2004);

- values (the worth and usefulness of ideals and customs (Bradley and Schrom, 2004).Bear in mind that values do change over time and differ according to different circumstances. At the end of the day, however, moral values include aspects such as fairness, honesty, and responsibility (Brandl and Maguire, 2002).

Business ethics is a particular context to which ethics can be applied. According to Niemanand Bennett (2006:239), business ethics becomes apparent ".where the moral duties of ethics apply to the activities and goals of an organisation."Therefore, business ethics is the discipline that deals with the values and rules of behaviour of society, while pursuing the objectives of an organisation. Bradley and Schrom (2004) describe business ethics as rules that govern the conduct of the profession that a person pursues. However, much more emphasis is placed on profession-specific norms of behaviour than on business ethics.

Hertz (2006) states that organisations have a duty to regard all those affected in every decision it takes. Ethically questionable behaviour may have enabled organisations to acquire a competitive advantage in the past, but today such practices are frowned upon on a societal level. As mentioned, competitive pressures could result in dishonesty, focusing on short-term benefits, and compromising quality in return for expediency (Harvey, 2002). Simms (2006) also indicates that too little attention is being paid to the long term, due to extreme demands on people in organisations. Behaving ethically has a very important place in business operations and performance. However, focusing on the short term, cutting corners, and placing short-term financial gains above all else will not ensure business success, and is the breeding ground for unethical behaviour.

Ethical codes, compliance officers, and ethics departments are established in organisations to avoid the bad publicity that follows ethical blunders (Harvey, 2002). In the end, however, ethical behaviour begins and ends with the individual. Therefore, organisations must be cautious as to who they employ and with whom they form relationships (Monaghan, 2005). Brandl and Maguire (2002) mention that guaranteeing ethical behaviour is a huge challenge, but organisations cannot afford to ignore this challenge, as ethical behaviour contributes to long-term sustainability.

Friedman (1970) postulated that the only responsibility an organisation really has is toward its own shareholders. Friedman's Shareholder Theory purports that managers (who, in turn, represent the organisation) should manage the organisation in the best interests of the shareholders 
by maximizing their return on investment (Rossouw and Van Vuuren, 2006). With increased emphasis on the rights of staff, protection of the natural environment and fair competition, however, this view has come under scrutiny, as the environment within which the organisation operates has evolved since Friedman presented it in 1970.

In reaction to Shareholder Theory, Freeman and Evan (1993:76) ask: "For whose benefit and at whose cost should the organisation be managed?"

What Freeman and Evan concluded was that there were several arguments that led to a rejection of Friedman's original stance. These included:

- Legal arguments: Many courts have ruled that the organisation has duties towards parties other than just shareholders, and the organisation should therefore balance the pursuit of shareholder interests with the interests of other stakeholders.

- Economic arguments: In contrast to the 'invisible hand' argument (according to which the organisation would automatically serve the greater good by serving shareholder interests), the reality of the situation is that the modern organisation has damaged and polluted the environment and disrupted society on a collective and an individual level (Rossouw and Van Vuuren, 2006). Organisations reaped the benefits of their actions, but were not willing to take responsibility for the consequences of their actions. This led to organisations being heavily regulated, so as to prevent them from transferring the cost of their actions to society at large.

These arguments show that managers of organisations need to serve the interests of more than just shareholders. According to Rossouw and Van Vuuren (2006), managers:

- Have an obligation not to violate the legitimate rights of others, and

- Are responsible for the effects of their actions on others.

Different literature sources reveal that the exact number and labelling of stakeholders differ, with some authors identifying 6 stakeholder groups, while others expand this to 11 groupings (Carroll, 1999; Griseri and Seppala, 2010; Lewis. Goodman and Fandt, 1998; Volberda, Morgan, Reinmoeller, Hitt, Ireland and Hoskins, 2011). Stakeholders identified by various authors include owners (shareholders), employees, suppliers, customers, environmental groups, media, society, local communities, managers, business partners, trade unions, and government.

Carroll (1999) provides a classification of stakeholders based on the nature of their relationship with the organisation, and identifies two broad categories:

- Primary stakeholders: Those who have a formal, official, or contractual relationship with the organisation, e.g., shareholders, employees, suppliers, and customers; and

- Secondary stakeholders: Those indirectly affected by the activities of the organisation, e.g., environmental groups, society at large, the media, consumer groups, and the government.

Within these groupings, one can then identify specific stakeholders.

Critique against the Stakeholder Theory centres around the diverse interests that emanate from these stakeholder groupings. Goodpaster (1993) purports that if managers view all the interests of diverse stakeholders as equal, they will be reduced to little more than public institutions, as public institutions have an obligation to act in the best interests of the broader society within which it functions. Goodpaster (1993) agrees that managers' primary responsibility is toward shareholders (a fiduciary obligation). However, this fiduciary obligation should not result in maximising profits at the expense of other stakeholders. The organisation therefore has a moral obligation towards all stakeholders of the organisation (Goodpaster 1993).

Developed from Stakeholder Theory, the concept of corporate citizenship (CC) endeavours to (Van Marrewijk, 2003:98|".connect business activity to the broader social accountability and service for mutual benefit."

This view equates the organisation to a member of society, with rights and accompanying obligations to which it should be subservient (Waddell, 2000). CC is a view that impresses characteristics of a person upon the organisation. "Person" does not imply a natural person, but rather a social construct. It implies legal personality, with the organisation being able to enter into legally binding contracts, negotiate, and be accountable for its actions. This, in turn, translates into rights, obligations, and responsibilities to which the organisation needs to adhere. Although Friedman (1970) did purport that the only responsibility a business organisation has is to maximise profit, he did concede that an organisation is a social construct and, as such, has characteristics associated with humans ascribed to it. He did, however, also stress that these are done on behalf of the organisation and not by the organisation.

Criticism of the suitability of the term 'corporate citizenship' aside, the notion of CC exists, whether within the organisation or in the eye of stakeholders. As such, stakeholders have certain expectations of organisations in terms of 'doing the right thing.' Certainly, one would assume that organisations are not oblivious to these expectations, but the extent to which these expectations are fulfilled is debatable. 


\section{THE INFLUENCE OF CULTURE}

It must be remembered that different countries may have different ideals about the conduct of organisations as members of their respective societies. In this regard, Hofstede (Hofstede, 1991; Hofstede, 2001)) provides a seminal understanding of national value differences within organisations. He identified four dimensions along which values of employees in 53 different countries vary (Hofstede, 1991):

- Power distance: The extent to which people believe that power is distributed unevenly in the organisation;

- Individualism: The extent to which people are expected to look out for themselves;

- Masculinity: The extent to which strict gender roles exist; and

- Uncertainty avoidance: The extent to which people feel threatened by uncertain or unknown situations.

The empirical work of Hofstede (and others, most noticeably Trompenaars, 1996) suggests that countries that score similarly in terms of different dimensions could be grouped together in "country clusters" that will exhibit similarities in terms of values (Luthans and Hodgetts, 1997). This does not necessarily mean that ethical principles along the lines of specific dimensions will be identical within these country clusters, but the probability is high that ethical principles based on the dimension investigated will overlap within these country clusters.

Country and cultural differences in terms of ethical principles in business necessitates an examination of whether these differences can be justified. This further fuels the debate between ethical relativism (the stance that different ethical principles apply in different regions) and ethical universalism (the search for a single, universal set of ethical principles, applicable to all). Somewhere between these poles resides Stakeholder Theory, which, on the one hand, recognises that different stakeholders have differing interests and are affected differently by decisions taken in the organisation. On the other hand, Stakeholder Theory also realises the necessity of satisfying the needs (or benefiting) all stakeholders (Fisher and Lovell, 2009). This reminds strongly of the Rawlsian Difference Perspective (Rawls, 1971), which stipulates that inequalities should be arranged in such a way that they are reasonably expected to be to everyone's advantage. Ethical systems and standards can, therefore, be tested against the Difference Principle, and if they do not benefit all stakeholders involved, they should be deemed inappropriate (Rawls, 1971). Therefore, Stakeholder Theory in its most stringent application should conform to the Difference Perspective.

Just as societal culture has a distinctive influence on business ethics, so too will societal culture influence how individuals perceive and experience efforts by organisations to act ethically.

\section{EXPLORATORY MODEL EMPLOYED}

This paper considers whether students are of the opinion that organisations act in an ethical manner or not; in other words, "Do they practise what they preach?" In this regard, it would be prudent to consider the behaviour organisations exhibit towards their stakeholder groupings, as this would represent an obvious manifestation of the ethical conduct of organisations. From the preceding literature review, however, it is apparent that numerous stakeholder groups exist, and that the exact number of stakeholders can differ from organisation to organisation.

Consequently, the decision was made to collapse certain groupings together and to use stakeholder groups loosely based on the Strategic Stakeholder Grouping classification presented by Post, Preston, and Sachs (2002). According to this classification, stakeholders are categorised on the basis of their strategic environments. This, in turn, provides the organisation with direction in terms of how to deal with different stakeholders. The Strategic Stakeholder Grouping classification proposes three groups of stakeholders (Post et al, 2002):

- Core stakeholders: Those vital to the existence of the organisation, such as investors, employees, and customers;

- Competitive environment stakeholders: These stakeholders define the company's competitive position in a particular industry and market, e.g. business partners, unions, competitors, and regulatory authorities; and

- External environmental stakeholders: These stakeholders challenge the company to foresee and respond to developments as they arise, e.g. social and political actors.

- For the purposes of this study, five stakeholder groups were used:

- The environment (including environmental groups), an external environmental stakeholder group;

- Staff (encompassing employees and managers), a core stakeholder group;

- The community at large (encompassing society and local communities), an external environmental stakeholder group;

- Regulatory bodies, an external stakeholder group, and

- Competition (focusing on the whole competitive landscape), a competitive environment stakeholder group.

Shareholders were not been included as one of the stakeholder groups in this study, as the crux of stakeholder theory and corporate citizenship revolves around the way an organisation treats the stakeholders towards whom the organisation has a moral obligation. It is implicit that organisations act responsibly toward shareholders. 
The decision to extract three distinct groupings from the external environmental stakeholder group of Post et al. (2002) was born out of:

- The increased emphasis on environmental issues,

- The increased emphasis on social accountability and the impact of the business on society, and

- The increased emphasis on governance and fiduciary responsibility.

From these groupings, the study endeavoured to test the following hypotheses:

- Ethical conduct towards the environment (ENV) H1: Organisations do not act in the best interests of the environment.

Alternative: Organisations act in the best interest of the environment.

- Ethical treatment of staff (STA)

H2: Organisations do not act in the best interests of staff.

Alternative: Organisations act in the best interests of staff.

- Ethical conduct toward the community at large (COM) H3: Organisations do not act in the best interests of the broader community.

Alternative: Organisations act in the best interests of the community.

- Ethical conduct toward regulators (REG)

H4: Organisations are not committed to being good corporate citizens.

Alternative: Organisations are committed to being good corporate citizens.

- Ethical conduct in competition (COP)

H5: Organisations do not compete fairly.

Alternative: Organisations compete fairly.

These constructs can be portrayed as follows [Figure 1]:

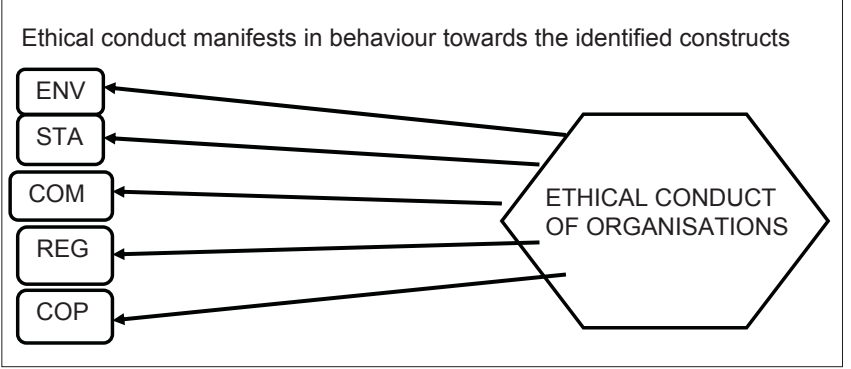

Figure 1: Exploratory model of manifestations of ethical behaviour by organisations

\section{RESEARCH DESIGN}

A positivistic paradigm was adopted in order to satisfy the aim of this study. Positivism is associated with deductive reasoning aimed at inferring universal principles applicable to a certain research population from a representative sample (Collins and Hussey, 2003). This study employed an exploratory, survey design to collect primary data. As mentioned, not much work has been done on how students view the ethical conduct of organisations. Consequently, this study endeavoured to deepen our understanding of this issue.

The research population comprised business students at the University of Johannesburg (South Africa) and the Krakow School of Business, a subsidiary of the Krakow University of Economics in Poland. Students in the first and second year of study were not used, as these students were deemed not to be familiar enough with the notions of business ethics and corporate citizenship.

Final-year and post-graduate students were used in this study. This was very important as third-year (and above) students would, firstly, have more theoretical knowledge on the issues under investigation, and, secondly (and most importantly), there was a greater probability that senior and post-graduate students would be employed, and would therefore be able to comment on the ethical conduct exhibited by business organisations.

Non-probability sampling in the form of a quota sample was employed. A target of 250 respondents was decided on for each country, culminating in a combined target of 500 respondents. 250 respondents per country represented a number from which statistically relevant conclusions could be drawn.

The study employed a customised measuring instrument that was developed by the authors. The items that measured how students perceived the ethical conduct of business organisations were derived from literature, and were measured on a six-point Likert scale. The measuring instrument collected demographic data (Section A) and data pertaining to the five constructs that comprise the conceptual model (Section B - see Annexure A). In South Africa, the measuring instrument was administered in March 2010 amongst students on the Bunting Road Campus and the Kingsway Campus of the University of Johannesburg. Student participation was voluntary, and surveys were administered directly in lecture venues by a student assistant. In Poland, the measuring instrument was administered in January and February 2010 on the main campus of the Krakow University of Economics on Rakowicka Street, Krakow, as this is where the Krakow School of Business is located. Again, participation was voluntary, and surveys were administered directly in lecture 
venues by an assistant from the business school. The measuring instrument was translated into Polish.

Data analysis included quantitative reliability tests, and descriptive as well as inferential statistics. Cronbachalpha reliability tests were performed on each construct to measure the internal reliability of the constructs employed. 'Reliability' relates to the extent to which a particular data collection approach will yield the same results when used on other occasions (Lancaster, 2005). The Cronbachalpha computation provides an index that is scored between 0 and 1 , with a score of 0.7 or higher being deemed reliable (Burns and Burns, 2008).

Descriptive statistics were compiled to assess the nature of the normal distributions of each construct. This would illustrate how commerce students perceived the ethical behaviour of business organisations - positive or negative - in terms of the identified constructs. Here, the mean value of each construct was analysed against the median value of the measuring instrument. As the scale was coded from $1=$ Always to $6=$ Never, the median value was 3.5.Therefore, 3.5 was an objective 'midway' in determining whether opinion was negative or positive towards a given construct (lower than 3.5 was considered "positive" and higher than 3.5 was considered "negative"). The choice of a six-point scale was deliberate so as to attempt to discourage notions of central tendency from respondents. To compare similarities between the SA and Polish datasets, independent sample t-tests were performed. This implied first conducting Levene's test for equality of variance in order to assure similarity of variance between the two groups. Where statistically significant differences in means were encountered, the effect size (eta squared) also needed to be calculated to provide an indication of the magnitude of the differences between the means of the two groups. Lastly, one sample $t$-test was performed to test the hypotheses derived from the conceptual model.

\section{RESEARCH FINDINGS}

The South African survey (ZA) realised 258 survey questionnaires, of which 251 were usable. The Polish survey (PL) rendered 262 questionnaires, of which 257 were usable. The survey yielded a total of 508 usable questionnaires.

Table 1 reflects the demographic data applicable to the sample. $72.5 \%$ of the ZA respondents and $94.5 \%$ of the PL respondents were employed at the time of completing the questionnaire. This is crucial, as the respondents had working experience and could express valid opinions about the ethical behaviour of organisations. In terms of experience, $78.4 \%$ of the ZA respondents and $97 \%$ of the PL sample had work experience. This underscores that the respondents were in a position to express valid opinions concerning the ethical conduct of organisations.
Reliability of the measuring instrument

Table 2 indicates the Cronbach'salpha values per construct. With the exception of "Ethical conduct in competition" (COP), the Cronbach'salpha values range from 0.55 to 0.79 . This is satisfactory for exploratory research (Scheepers, Bloom and Hough, 2008). Althayde (2003) and Nunally (1978) are also of the opinion that $\alpha>0.5$ is acceptable for exploratory research. As thescales were made up of a low number of items (4 - 6), Cronbach values could be low. Therefore, the mean inter-item correlations were also scrutinised. Here, a range of 0.2 to 0.4 indicates internal consistency. Most of the mean inter-item correlations did fall within the specified parameters [Table 2]. The notable exceptions were "Ethical conduct toward regulators" (REG) for South Africa (but here the alpha value was high enough

\begin{tabular}{lcc}
\hline Table 1: Demographic data & & \\
\hline Variable & ZA & PL \\
\hline Total usable questionnaires & 251 & 257 \\
Gender & & \\
Male & 117 & 89 \\
Female & 134 & 168 \\
Age & & \\
Under 20 & 6 & 0 \\
$21-30$ & 188 & 156 \\
$31-40$ & 45 & 73 \\
$41-50$ & 10 & 22 \\
Above 50 & 2 & 6 \\
Highest qualification & & \\
High school & 30 & 0 \\
Post school certificate/diploma & 43 & 2 \\
Degree & 139 & 177 \\
Postgraduate degree & 33 & 62 \\
More than one postgraduate degree & 6 & 16 \\
Employment status & & \\
Not employed & 69 & 13 \\
Employed part-time & 55 & 31 \\
Permanently employed & 127 & 212 \\
Employment history & & \\
No experience & & \\
Less than 5 years' experience & 54 & 128 \\
Between 5 and 10 years' experience & 45 & 63 \\
More than 10 years' experience & 45 & 58 \\
\hline
\end{tabular}

\begin{tabular}{lccccccc}
\hline Table 2: Reliability statistics & & & & \\
\hline Construct & $\begin{array}{c}\text { Number } \\
\text { of items }\end{array}$ & \multicolumn{2}{c}{$\begin{array}{c}\text { Cronbach's } \\
\text { alpha }\end{array}$} & & \multicolumn{2}{c}{$\begin{array}{c}\text { Mean } \\
\text { inter-item } \\
\text { correlations }\end{array}$} \\
\cline { 3 - 4 } & & ZA & PL & ZA & PL \\
\hline $\begin{array}{l}\text { Ethical conduct toward } \\
\text { the environment (ENV) }\end{array}$ & 5 & 0.63 & 0.55 & 0.27 & 0.20 \\
$\begin{array}{l}\text { Ethical conduct } \\
\text { towards staff (STA) }\end{array}$ & 4 & 0.69 & 0.67 & 0.40 & 0.39 \\
$\begin{array}{l}\text { Ethical conduct toward } \\
\text { the community (COM) }\end{array}$ & 6 & 0.74 & 0.77 & & 0.34 & 0.36 \\
$\begin{array}{l}\text { Ethical conduct toward } \\
\text { regulators (REG) }\end{array}$ & 5 & 0.79 & 0.68 & 0.49 & 0.35 \\
$\begin{array}{l}\text { Ethical conduct in } \\
\text { competition (COP) }\end{array}$ & 5 & 0.32 & 0.10 & 0.08 & 0.02 \\
\hline
\end{tabular}


to consider the construct reliable), and COP for South Africa and Poland.

As a result of alpha values of 0.32 and 0.10 , the construct COP was discarded, as this construct seemed to have evoked inconsistent responses. In summary, all constructs (except for $\mathrm{COP}$ ) were deemed reliable.

\section{Descriptive statistics}

Descriptive statistics, such as the mean, median, variance, and standard deviation were calculated for the survey [Table 3]. The mean for each construct is of importance, as this indicates the opinion of respondents toward a construct.

Five items (B1, B3, B11, B13, and B21)constituted "Ethical conduct toward the environment" (ENV).The ZAENV mean value was 4.154 , a 0.654 negative deviation from the measuring instrument median of 3.5. A negative deviation implies that the opinion of the respondents toward this construct was negative (albeit slightly); therefore, the ZA respondents were of the opinion that organisations do not behave in the best interests of the environment. The PL ENV mean value was 4.193 , a 0.693 deviation to the negative. "Ethical conduct toward staff" (STA) comprised four items (B4, B6, B8, and B10). The ZA STA mean was 3.475 , a 0.025 deviation to the positive, Positive deviation implies that the opinion of the respondents toward this construct was positive (albeit very slightly); thus, the ZA respondents were of the opinion that organisations behave in the best interests of their staff. The PL mean for this construct was 3.800 , a deviation of 0.300 to the negative side of the scale. "Ethical conduct toward the community" (COM) consisted of six items (B12, B14, B16, B20, B22, and B23). The ZA mean value was 3.427 , a 0.073 positive deviation. The PL COM mean value was 4.012 , a 0.512 deviation to the negative side of the scale. "Ethical conduct toward regulators" (REG) consisted of five items (B7, B9, B17, B18, and B24). The ZA REG mean was 3.651, representing a 0.151 deviation to the negative, whereas the PLREG value was 3.852 , a 0.352 deviation to the negative side of the scale. COP was deemed internally unreliable, and was discarded. No further statistical analysis was applied to this construct.

It is apparent that the deviations are quite small (ranging from 0.025 to 0.654 ) and, as such, can be seen to be neutral and meaningless. This argument has merit, but in the context of this study, event neutrality is meaningful, as it would represent something other than what the organisations profess in terms of ethical conduct. If organisations are as ethical as they profess to be, respondents would recognise this and score them as such on the scale employed. Thus, scores gravitating around the neutral point of this scale imply that respondents view the ethical behaviour of organisations in their respective countries somewhat differently.

\section{South Africa / Poland comparisons}

It soon became evident that the independent sample t-tests alone would not deliver satisfactory results, as all the significance levels for Levene's test were below 0.05

\begin{tabular}{|c|c|c|c|c|c|c|c|}
\hline Construct & Country & Mean & Mean Std error & Median & Variance & Std deviation & Difference \\
\hline \multirow[t]{2}{*}{ ENV } & $\mathrm{ZA}$ & 4.154 & 0.0410 & 4.200 & 0.422 & 0.650 & -0.654 \\
\hline & $\mathrm{PL}$ & 4.193 & 0.0292 & 4.200 & 0.219 & 0.469 & -0.693 \\
\hline \multirow[t]{2}{*}{ STA } & ZA & 3.475 & 0.04677 & 3.333 & 0.547 & 0.740 & 0.025 \\
\hline & PL & 3.800 & 0.0340 & 4.000 & 0.298 & 0.546 & -0.300 \\
\hline \multirow[t]{2}{*}{ COM } & ZA & 3.427 & 0.0447 & 3.500 & 0.500 & 0.707 & 0.073 \\
\hline & PL & 4.012 & 0.0339 & 4.000 & 0.296 & 0.544 & -0.512 \\
\hline \multirow[t]{2}{*}{ REG } & ZA & 3.651 & 0.0475 & 3.750 & 0.565 & 0.752 & -0.151 \\
\hline & PL & 3.8525 & 0.0331 & 4.000 & 0.282 & 0.531 & -0.352 \\
\hline
\end{tabular}

ENV: Ethical conduct towards the environment, STA: Ethical treatment of staff, COM: Ethical conduct toward the community at large, REG: Ethical conduct toward regulators

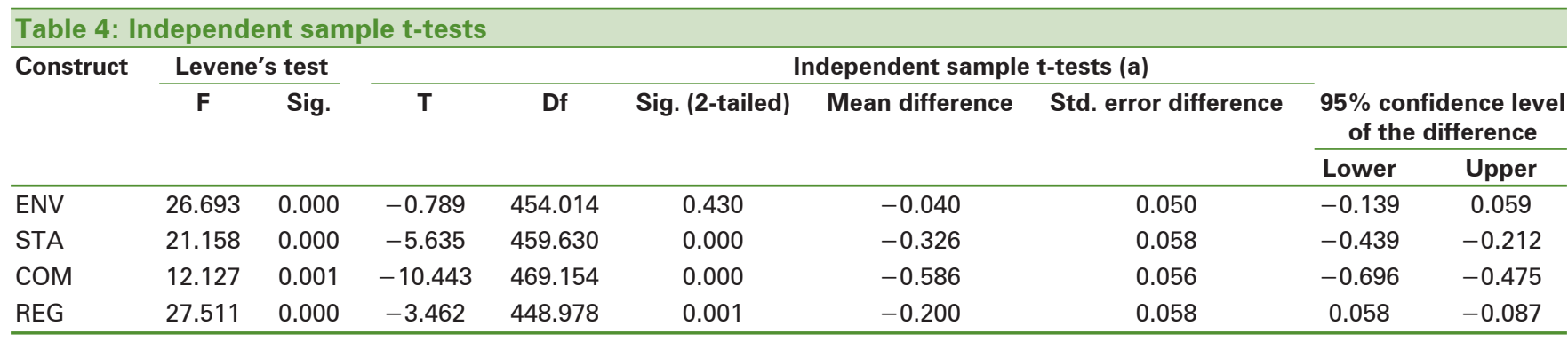

ENV: Ethical conduct towards the environment, STA: Ethical treatment of staff, COM: Ethical conduct toward the community at large, REG: Ethical conduct toward regulators (a) As Levene's test delivered no $P$ values higher than 0.05 , equal variance cannot be assumed 
[Table 4]. It was therefore decided to combine the results of the independent sample tests with the Mann-Whitney test in an effort to triangulate methods. Upon completion of the independent sample tests, it was evident that the construct ENV did not reflect a statistically significant difference in mean scores. However, all other constructs did reflect statistically significant differences in mean scores, as Table 4 indicates. Therefore, South Africans and Poles perceived the ethical conduct of organisations towards the environment in the same way, whereas they perceived the ethical conduct of organisations towards staff, the community, and regulators differently.

(a) As Levene's test delivered no $P$ values higher than 0.05 , equal variance cannot be assumed.

The Mann-Whitney test [Table 5] delivered similar results as the independent sample t-tests, indicating that "Ethical conduct towards the environment" (ENV) did not yield a statistically significant difference in means, but all other constructs reflected statistically significant differences in mean scores. As normality is a prerequisite for the Mann-Whitney test, the Kolmogorov-Smirnov test needed to be performed.

The Kolmogorov-Smirnov test indicated that normality was not present in the data [Table 6]. This could be ascribed to the fact that it is sensitive to large sample sizes. The Normal Q-Q plots, however, showed that normality could be assumed in the data.

Both the independent sample t-tests and the Mann-Whitney test delivered the same results, namely that ENV exhibits no statistically significant difference between countries, but that "Ethical conduct toward staff" (STA), "Ethical conduct toward the community" (COM), and "Ethical conduct toward regulators" (REG)did yield statistically significant differences in mean values between ZA and PL. With such large sample sizes for ZA and PL, it is prudent to assess the effect size (eta squared) of the difference in means as well [Table 7], as this indicates the magnitude of the differences between the means of the two groups, and can indicate whether or not a difference between means is merely coincidental. In other words, this test assesses whether these differences are meaningful or not.

COM reflected a large effect, STA a moderate effect, and REG a small effect when interpreted according to Cohen's guidelines (Pallant, 2007). Therefore, the differences in means for REG seem to be coincidental, whereas the differences in means for STA and COM are not merely coincidental and warrant further investigation.

\section{Hypothesis testing}

To prove that the positive and negative mean deviations were statistically significant and not the results of coincidence, the findings were subjected to one sample $\mathrm{t}$-test. This also served as the basis for rejecting or accepting the hypotheses associated with the exploratory model. Table 8 indicates that ZA data, ENV, and REG had t-values larger than two, and significance levels of 0.05 , indicating statistical significance. The difference between STA and COM had no statistical significance.

For the Polish data, all constructs exhibited t-values larger than two and significance levels of $<0.05$, which rendered all constructs for the PL sample statistically significant in terms of the opinions expressed by respondents, as Table 8 reflects.

However, statistical significance only proves that the findings were not the result of coincidence, but does not imply that these findings are meaningful. Again, one needs to calculate the effect size for these results to be able to deduce meaningfulness of the data. In this regard, Cohen's d was calculated as the effect size for the one sample $t$-test (Cohen, 1988). To interpret the effect sizes, a value of 0.2 to 0.5 is regarded as small, 0.5 to 0.8 is medium, and 0.8 and above is large. The effect sizes are portrayed in Table 9.

\begin{tabular}{lcc}
\hline Table 5: Mann-whitney U test per construct \\
\hline Construct & Mann-whitney U & Asymp. sig (2-tailed) \\
\hline ENV & 31580.000 & 0.682 \\
STA & 22866.500 & 0.000 \\
COM & 15530.000 & 0.000 \\
REG & 26210.000 & 0.000 \\
\hline
\end{tabular}

ENV: Ethical conduct towards the environment, STA: Ethical treatment of staff, COM: Ethical conduct toward the community at large, REG: Ethical conduct

\begin{tabular}{lcccc}
\hline \multicolumn{3}{l}{ Table 6: Kolmogorov-smirnov test for normality } \\
\hline Construct & Country & \multicolumn{3}{l}{ Kolmogorov-smirnov (a) } \\
\cline { 3 - 5 } & & Statistic & Df & Sig. \\
\hline ENV & ZA & 0.086 & 251 & 0.000 \\
\multirow{2}{*}{ STA } & PL & 0.110 & 257 & 0.000 \\
& ZA & 0.110 & 251 & 0.000 \\
COM & PL & 0.149 & 257 & 0.000 \\
& ZA & 0.096 & 251 & 0.000 \\
REG & PL & 0.143 & 257 & 0.000 \\
& ZA & 0.089 & 251 & 0.000 \\
& PL & 0.135 & 257 & 0.000 \\
\hline
\end{tabular}

ENV: Ethical conduct towards the environment, STA: Ethical treatment of staff, COM: Ethical conduct toward the community at large, REG: Ethical conduct (a) Lilliefors significance correction

\begin{tabular}{|c|c|}
\hline Construct & Effect size \\
\hline ENV & N/A (no statistically significant difference in means) \\
\hline STA & 0.06 \\
\hline COM & 0.18 \\
\hline STA & 0.02 \\
\hline
\end{tabular}

ENV: Ethical conduct towards the environment, STA: Ethical treatment of staff, COM: Ethical conduct toward the community at large, REG: Ethical conduct 


\begin{tabular}{|c|c|c|c|c|c|c|c|}
\hline \multirow[t]{3}{*}{ Country } & \multirow[t]{3}{*}{ Construct } & \multicolumn{6}{|c|}{ Test value $=3.5$} \\
\hline & & \multirow[t]{2}{*}{$\mathbf{T}$} & \multirow[t]{2}{*}{ Df } & \multirow[t]{2}{*}{ Sig. (2-tailed) } & \multirow[t]{2}{*}{ Mean difference } & \multicolumn{2}{|c|}{$\begin{array}{l}95 \% \text { confidence } \\
\text { interval of the } \\
\text { difference }\end{array}$} \\
\hline & & & & & & Lower & Upper \\
\hline \multirow[t]{4}{*}{ ZA } & ENV & 15.936 & 250 & 0.000 & 0.653 & 0.573 & 0.734 \\
\hline & STA & -0.541 & 250 & 0.589 & -0.025 & -0.117 & 0.067 \\
\hline & COM & -1.639 & 250 & 0.102 & -0.073 & -0.161 & 0.015 \\
\hline & REG & 3.183 & 250 & 0.002 & 0.151 & 0.058 & 0.245 \\
\hline \multirow[t]{4}{*}{ PL } & ENV & 23.725 & 256 & 0.000 & 0.693 & 0.636 & 0.751 \\
\hline & STA & 8.823 & 256 & 0.000 & 0.300 & 0.233 & 0.367 \\
\hline & COM & 15.108 & 256 & 0.000 & 0.512 & 0.446 & 0.579 \\
\hline & REG & 10.606 & 256 & 0.000 & 0.352 & 0.286 & 0.417 \\
\hline
\end{tabular}

ENV: The hypothesis is accepted and alternative hypothesis is rejected, STA: Statistically insignificant results, COM: Statistically insignificant results, REG: Hypothesis accepted and alternative hypothesis rejected

\begin{tabular}{llcl}
\hline \multicolumn{4}{l}{$\begin{array}{l}\text { Table 9: Effect sizes (Cohen's d) for constructs per } \\
\text { country }\end{array}$} \\
\hline Country & Construct & Effect size & Meaning \\
\hline South Africa & ENV & 1.00 & Large \\
& STA & -0.03 & Small \\
& COM & -0.10 & Small \\
& REG & 0.21 & Small \\
Poland & ENV & 1.47 & Large \\
& STA & 0.54 & Moderate \\
& COM & 0.94 & Large \\
& REG & 0.66 & Moderate \\
\hline
\end{tabular}

ENV: The hypothesis is accepted and alternative hypothesis is rejected, STA: Statistically insignificant results, COM: Statistically insignificant results, REG: Hypothesis accepted and alternative hypothesis rejected, COP: Inconclusive, as the construct was deemed unreliable, ENV: Hypothesis accepted and alternative hypothesis rejected, STA: Hypothesis accepted and alternative hypothesis rejected, COM: Hypothesis accepted and alternative hypothesis rejected, REG: Hypothesis accepted and alternative hypothesis rejected, COP: Inconclusive, as the construct was deemed unreliable

With the exception of ENV, all effect sizes for the South African data were small. Thus, only the opinion expressed toward organisations' ethical treatment of the environment (ENV) can be viewed as a meaningful opinion. The Polish data presented a different picture, with all effect sizes being either moderate or large, indicating some degree of meaningfulness of these findings.

The following can therefore be concluded as far as the stated hypotheses are concerned:

\section{Discussion of findings}

The statistical analysis for this study are summarised in Table 10.

The findings indicate that the following opinions are statistically significant:

- ZA respondents are of the opinion that business organisations do not act in the best interests of the environment or the community at large.
- PL respondents are of the opinion that business organisations do not act in the best interests of the environment, their staff, the community at large, or regulatory authorities.

Also, the following opinions are meaningful from a practical point of view:

- ZA respondents are of the opinion that business organisations do not act in the best interests of the environment.

- PL respondents are of the opinion that business organisations do not act in the best interests of the environment or the community at large.

When the similarities between the ZA and PL opinions are investigated, it is evident that South Africans and Poles feel the same about how organisations treat the environment (ENV). In the case of ethical conduct toward the community at large (COM), this difference seems to be coincidental, but the difference in opinion regarding organisations' treatment of staff (STA) and ethical conduct towards regulators (REG) seems to be more than mere coincidence. The Conclusion section will shed more light on possible reasons for this difference.

In summary, all statistically significant measures of the different constructs presented seemed to support the stated hypotheses, although one should take into account that effect sizes do not always indicate that these measures are meaningful. Also, apart from respondents' opinions on how organisations act toward the environment, all other constructs exhibited differences of opinion, although the difference in opinion that exists in terms of how organisations treat their staff seems to be coincidental.

\section{CONCLUSION}

From the above discussion, the exploratory model for ZA, provided in Figure 2, can be confirmed. 
The ethical conduct of South African organisations towards the physical environment (ENV) and their ethical conduct towards regulatory bodies (REG) are questioned by ZA respondents. They are, therefore, seemingly distrustful of the intentions of organisations to comply with environmental legislation and serve the interests of the environment. These findings tend to converge on the notion that organisations act in their own best interests. As far as STA and COM are concerned, the ZA findings reveal that the students surveyed have a more lenient view of how organisations treat their staff and the community at large. However, these findings are not statistically insignificant. This does not mean that what was reflected is necessarily incorrect, but rather that that it cannot be proven that this sentiment is more that coincidence. As already mentioned, COP was deemed unreliable. This does not imply that ethical conduct in competition is not of importance, but rather that the items pertaining to that specific construct were not properly understood by the ZA respondents.

The PL exploratory model, provided in Figure 3, can be confirmed.

From the PL findings, it is obvious that Polish respondents harbour significantly negative sentiments concerning the ethical conduct of organisations, reflecting mistrust of the ethical intentions of organisations on the whole. Again, ethical conduct in competition (COP) was deemed

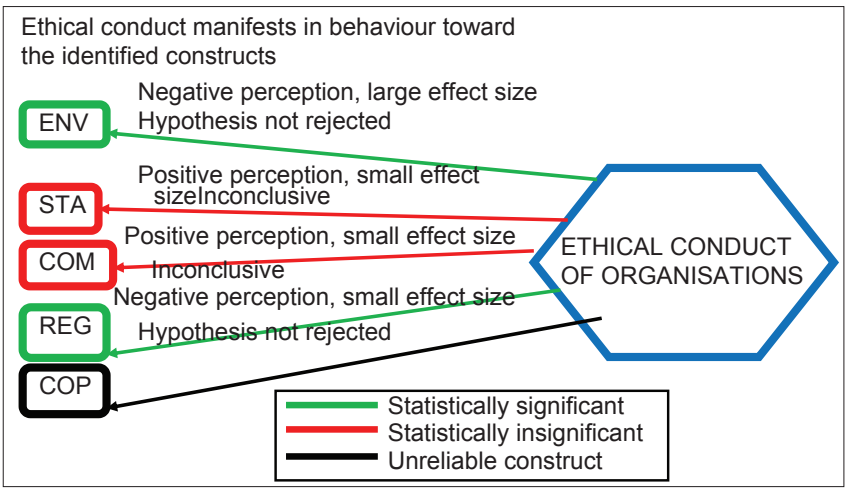

Figure 2: Confirmation of exploratory model for South Africa (ZA) unreliable and discarded from the study, implying that the items pertaining to this construct were not properly understood by the PL respondents.

When comparing the mean scores for the different countries for each of the theoretical constructs, differences do exist. In terms of how respondents view the behaviour of organisations towards the environment, no difference exists, indicating that South Africans and Poles agree in their perception of irresponsible treatment of the physical environment by organisations. As for the perception of how organisations act toward the greater community, the effect size is small, indicating that the difference in mean scores is (more likely than not) merely coincidental. For all intents and purposes, Polish and South African opinions of the ethical intentions of organisations towards the broader community are similar.

As far as the treatment of their staff by organisations is concerned, the effect size was moderate, indicating that the difference in mean scores was more than mere coincidence. Although the ZA opinion for this construct is deemed statistically insignificant, the difference between the mean scores of the two countries warrants explanation. It must be taken into consideration that the Polish workforce still consists of a large percentage of people who were economically active under Communist rule. Although Poland was instrumental in the demise of Communism

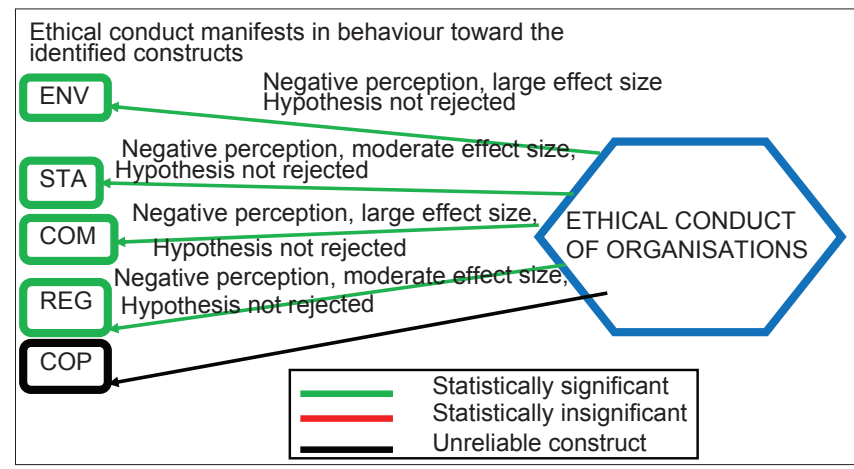

Figure 3: Confirmation of exploratory model for Poland (PL)

\begin{tabular}{|c|c|c|c|c|c|c|c|}
\hline Construct & Country & $\begin{array}{l}\text { Reliable } \\
\text { construct? }\end{array}$ & Opinion & $\begin{array}{l}\text { Statistically } \\
\text { significant? }\end{array}$ & Effect size & $\begin{array}{l}\text { Significant difference } \\
\text { in means? }\end{array}$ & $\begin{array}{l}\text { Effect size } \\
\text { of difference }\end{array}$ \\
\hline \multirow[t]{2}{*}{ ENV } & ZA & Yes & Negative & Yes & Large & No & $\mathrm{N} / \mathrm{A}$ \\
\hline & $P L$ & Yes & Negative & Yes & Large & & \\
\hline \multirow[t]{2}{*}{ STA } & ZA & Yes & Positive & No & Small & Yes & Moderate \\
\hline & $P L$ & Yes & Negative & Yes & Moderate & & \\
\hline \multirow[t]{2}{*}{ COM } & ZA & Yes & Positive & No & Small & Yes & Small \\
\hline & $P L$ & Yes & Negative & Yes & Large & & \\
\hline \multirow[t]{2}{*}{ REG } & ZA & Yes & Negative & Yes & Small & Yes & Large \\
\hline & $P L$ & Yes & Negative & Yes & Moderate & & \\
\hline \multirow[t]{2}{*}{ COP } & ZA & No & $\mathrm{N} / \mathrm{A}$ & $\mathrm{N} / \mathrm{A}$ & $\mathrm{N} / \mathrm{Al}$ & N/A & N/A \\
\hline & PL & No & N/A & $\mathrm{N} / \mathrm{A}$ & N/A & & \\
\hline
\end{tabular}

ENV: The hypothesis is accepted and alternative hypothesis is rejected, STA: Statistically insignificant results, COM: Statistically insignificant results, REG: Hypothesis accepted and alternative hypothesis rejected, COP: Inconclusive, as the construct was deemed unreliable 
in Eastern Europe, many members of the older generation are distrustful of the intentions of free market business organisations (Stanek, 2008). Also, Polish society is a very conservative one, steeped heavily in Catholicism. This very conservative outlook could also be the basis for this difference in opinion, as South African society is more accepting and open to new ideas and change.

The most pertinent difference in opinion between the ZA and the PL data was found in terms of the ethical conduct of organisations towards regulators. The large effect size here is basis for further investigation and explanation. Despite a booming economy, Poland is seen (primarily by its own citizens) as being rife with corruption, not only in government, but also in business (Stanek, 2008). Poles view those with power as able to wheel and deal' to suit their own interests above all else. This suspicion could also be attributable to the conservative outlook of Polish society. Furthermore, the fall of Communism led to many loopholes and opportunities for personal gain, a trend that was frowned upon by the average Pole.

In summary, therefore, two of the reliable constructs delivered statistically significant differences in mean values with sufficient effect sizes so as not to be deemed coincidental. Therefore, Poles and South Africans differ in their opinions of ethical conduct exhibited by organisations in terms of these two constructs (STA and REG). This seems to support the Country Cluster notion of Hofstede (in Luthans and Hodgetts, 1997), whereby practices, and per definition also the beliefs, value systems, and opinions that underlie them, from different cultures can be grouped together according to their spatial proximity. Although separated by some $9000 \mathrm{kms}$, it could be argued that South Africa, through a legacy of being a former Dutch and British Colony, adopted certain typically European traits, hence the seeming overlap in opinions in terms of certain constructs.

\section{RECOMMENDATIONS AND MANAGERIAL IMPLICATIONS}

This study, firstly, highlights that there is a disconnect between what organisations are professing to be doing in terms of ethical conduct toward different stakeholders and how a sample of Polish and South African students perceive these actions. Secondly, in comparing Polish and South African opinion, it was evident that they feel the same about certain aspects of the ethical behaviour (treatment of the environment and of staff) of organisations, but differently about other aspects (treatment of the community and ethical conduct towards regulators by organisations). This suggests that ethical behaviour implies different things to different people and cultural groups. Organisations should take cognisance of these differences when deciding upon ethically appropriate behaviour.
A business is able to sustain itself by having managers and employees who are able to act morally and ethically. Managers must recognize and acknowledge the dignity and human rights of all stakeholders. It is necessary to formulate ethical codes so as to keep employees on a sound moral course and to maintain high ethical standards. Moral values cannot be disregarded, as these drive honesty and make way for strong social inclusiveness. Managers and employees need sets of values to guide their conduct and should be involved in the formulation of these codes. This needs to be a collaborative process. Companies should develop sustainable partnerships with their communities, and companies should honour their moral obligation to society, the environment, and all other stakeholders in their business. People often think of ethics as a list of rules, much like the Ten Commandments. The assumption is then that if something is not expressly prohibited, there is no cause for concern. However, moral behaviour is the obligation to look beyond self-interest and to focus on the concerns of others.

Educators also have a role to play in ensuring that individuals with sound moral standards enter the workplace. Although difficult, business ethics as a subject should be integrated into business courses or offered as a separate course. Ethical management practices should enjoy more attention in business and management courses. Students appear to adopt the attitudes of their professional reference groups before they even commence their professional careers. By using experienced business professionals as guest lecturers to address the issue, more graduates of good moral and ethical standing can enter the workforce.

The differences in opinion between the Polish and South African students highlight the importance of tailoring ethical behaviour on the part of the organisation. The study shows that different things are important to a greater or lesser degree in different areas. Therefore, ethics is not just about doing the right thing; it seems to be about doing the right thing at the right time and in the right place, which is, in essence a perspective that leans toward ethical relativism.

The study also indicates that the respondents have a negative perception of the ethical conduct of business organisations in general. Organisations should highlight instances where the organisation has taken the moral high ground in their business dealings. This, in turn, will be a benefit and could be incorporated in the corporate marketing strategies of organisations.

\section{LIMITATIONS AND AREAS FOR FUTURE RESEARCH}

A limitation of the study is that a student sample was drawn from one specific location (higher education institution) in only two countries. The findings are therefore not representative on a national level, but reflect only the views 
of those who participated in the study. However, on an exploratory level, the findings remain insightful. As the sample was drawn from the ranks of students studying toward a business or management qualification, it could be argued that surveying respondents on a topic related to their field of study could have led to some level of response bias. Attitudes of other students could be different, but then again, students not in the field of business or management might not be familiar with the notion of business ethics at all.

As an exploratory study, the measuring instrument needs refinement, as the reliability analysis showed that certain items need to be excluded and other items reversed. The construct of ethical conduct in competition (COP) needs to be redesigned, which is indicative of the difficulty in measuring this concept, as it has different meanings for different people. Translating the measuring instrument into Polish could also account for the (overall) lower Cronbach alpha values of the Polish sample, showing that this was a case of meaning being 'lost in translation.'

Also, the study needs to be taken wider, not only on a local level, but also internationally. Collecting data from numerous countries could show the sentiment toward the ethical intentions of organisations in different parts of the world.

\section{CONCLUSION}

There is evidence to suggest that people in different parts of the world distrust the ethical conduct of organisations. This does not bode well for organisations in an era when the role and function of the organisation in society is being seriously questioned. Rossouw and Van Vuuren (2006) quote six myths of business ethics, one being that the organisation pursues profit at all cost. Although exploratory, this research suggests that these types of myths can perpetuate if organisations are unaware what their stakeholders actually think of them.

\section{REFERENCES}

Abratt, R., Bendixen, M. and Drop, K. (1999). Ethical perceptions of South African retailers: Management and sales personnel. International Journal of Retail and Distribution Management, 27 (2), 91-105.

Bradley, G. and Schrom, D. (2004). Can We Use Science to Know Our Ends? Bioscience, 54 (4), 284-285.

Brandl, P. and Maguire, M. (2002). Codes of Ethics: A Primer on Their Purpose, Development, and Use. Journal for Quality and Participation, 25 (4), 8-12.

Carroll, A.B. (1999). Corporate Social Responsibility: Evolution of a definitional construct. Business and society. 38 (3), 268-295.

Clark, K. (2006). Who Are You Listening to? Chain Store Age, 82 (6), 32-35. Collis, J. and Hussey, R. (2003). Business Research: A practical guide for undergraduate and postgraduate students. Hampshire: Palgrave-McMillan. Cohen, J.W. (1988). Statistical power analysis for the behavioural sciences. Hillsdale: Lawrence Erlbaum Associates.

Dart, L. (2004). What is Ethics? PA Times, 27 (1), 4-4.

Emory, C.W. and Cooper, D.R. (1991). Business Research Methods. Irwin: Boston.
Fisher, C. and Lovell, A. (2009). Business ethics and values: Individual corporate and international perspectives. London: Prentice-Hall.

Freeman, R. and Evan, W. (1993). A stakeholder theory of the modern corporation: Kantian Capitalism. In: Beauchamp, T. and Bowie N. (Eds.) Ethical theory and business. New Jersey: Prentice-Hall.

Friedman, M. (1970). The social responsibility of business is to increase its profits. New York Times Magazine. p. 122-126.

Goodpaster, K.E. (1993). Business ethics and stakeholder analysis. In: White, T.I. (Ed.) Business Ethics: a philosophical reader. New York: MacMillan.

Griseri, P. and Seppala, N. (2010). Business Ethics and Corporate Social Responsibility. Hampshire: Cengage.

Grobler, P., Warnich, S., Carrell, M.R., Elbert, N.F. and Hatfield, R.D. (2006). Human Resource Management in South Africa. London: Thomson.

Harvey, E. (2002). Ethics Agents. Executive Excellence, 19 (12): 18.

Hertz, N. (2006). Doing the right thing is good forbusiness. New Statesman, 135 (4808), 20-20.

Hodgetts, R.M. and Luthans, F. (1997). International Management. New York: McGraw-Hill.

Hofstede, G. (1991). Cultures and organisations: Software of the mind. London: McGraw-Hill.

Hofstede, G. (2001). Culture's consequences. London: Sage.

Lancaster, G. (2005). Reseach Methods in Management. Burlington: Elsevier. Lewis, P.S., Goodman, S.H. and Fandt, P.M. (1998). Management: Challenges in the $21^{\text {st }}$ Century. Cincinnati: South Western.

Monaghan, E. (2005). Dear "E." New Mexico Business Journal, 29 (1), 28-29.

Nieman, G. and Bennett, A. (2006). Business management: $A$ value chain approach. Pretoria: Van Schaik.

Nunally, J.C. (1978). Psychometric theory. New York: McGraw-Hill.

Pallant, J. (2007). SPSS survival manual. New York: McGraw-Hill.

Post, J.E., Preston, L.E. and Sachs, S. (2002). Managing the extended enterprise: The new stakeholder view. California Management Review. 45 (1), 6-28.

Pastore, J.M. (2003). What's right? What's wrong? Ask a child. Fairfield County Business Journal, 42 (41), 46-46.

Rawls, J. (1971). A theory of justice. Cambridge: Harvard University Press. Rosenstand, N. (2005). The Moral of the Story: An Introduction to Ethics. New York: McGraw-Hill.

Rushton, K. (2002). Business ethics: A sustainable approach. Business Ethics: A European Review, 11 (2), 137-139.

Rossouw, D and van Vuuren, L. (2006). Business Ethics. Cape Town: Oxford University Press.

Samuelson, J.F. (2004). Going Beyond Business Ethics. Business and Economic Review, 50 (4),7-10.

Scheepers, M.J., Bloom, J.Z. and Hough, J. (2008).The development of an instrument to assess the enacted environment for corporate entrepreneurship in South Africa. Management Dynamics, 17 (4), 2-17.

Simms, J. (2006). The principles of profit. Director (00123242), 59 (10), 22-22. Stanek, A. (2008).Responsible education of managers at the universities in Cracow. In: Gasparski, W. (Ed). Responsible management Education. Warszawa: Academic and Professional Press.

Thompson, A.A., Strickland, A.J. and Gamble, J.E. (2007). Crafting and Executing Strategy: Text and Readings. Boston: Irwin.

Van Marrewijk, M. (2003). Concepts and Definitions of Corporate Sustainability. Journal of Business Ethics, 44 (2,3), 95-105.

Volberda, H.W., Morgan, R.E., Reinmoeller, P., Hitt, M.A., Ireland, R.D. and Hoskisson, R.E. (2011). Strategic Management: Competitiveness and Globalization. Hampshire: Cengage.

Waddell, S. (2000): A "win-win" role for civil society in business strategy. Journal for Non-profit Management, 4 (1), 24-43.

How to cite this article: Goldman G, Bounds M, Bula P, Fudalinski J. On the ethical conduct of business organisations: A comparison between South African and polish business management students. Afr J Bus Ethics 2012;6:75-87.

Source of Support: Nil, Conflict of Interest: None declared 
Annexure A - Items constituting Section B of the measuring instrument

1. Organisations are serious about protecting and caring for the environment

2. Society perceives organisations as competing fairly

3. Organisations dedicate a lot of resources to eliminate wastage and pollution

4. Organisations require staff to perform tasks with which they are not comfortable

5. Organisations actively consult with their communities concerning their business activities and the impact thereof on these communities

6. Society perceives organisations to act in the best interests of their employees

7. Organisations are "citizens" of society and, therefore, act as good citizens

8. Organisations value the efforts of their staff in terms of the work they do

9. I trust organisations' intentions of acting ethically

10. Organisations care about the well-being of their staff

11. Society believes that organisations act in the best interests of the environment

12. Organisations commit time and resources (i.e. take action) to the social challenges society faces (such as crime and HIV/AIDS)

13. Organisations will only act in the best interest of the environment if it promotes their business

14. Society perceives organisations to act in the best interest of society

15. Profit is of primary importance to an organisation

16. Organisations commit time and resources (i.e. take action) to the economic challenges society faces (such as unemployment and the impact of poverty)

17. An organisation is only accountable toward its shareholders

18. Organisations are truly committed to being good corporate citizens

19. An organisation has to put everything on the line to outsmart its competitors

20. Organisations are aware of the social challenges society faces (e.g. crime and HIV/AIDS)

21. Organisations put the interests of the environment above the interests of their shareholders

22. Organisations care about the difficulties faced by their communities

23. Being a good corporate citizen enhances organisational learning which, in turn, enables the organisation to understand the market it operates within much better

24. People in general trust organisations' intentions of acting ethically

25. Organisations are aware of the economic challenges society faces (such as unemployment and the impact of poverty) All items were measured using the six-point scale below:

$\begin{array}{lllll}\text { Always } & \text { Very often } & \text { Often } & \text { Seldom } & \text { Very seldom }\end{array}$

\section{AUTHOR}

Dr. Geoff Goldman* (University of Johannesburg, South Africa) Dr Goldman is a senior lecturer in the Department of Business Management at the University of Johannesburg. He is the coordinator of full research Master's and Doctoral programmes in the department. Dr Goldman has authored in excess of 30 conference papers, journal articles and books, mainly in the area of Strategic Management. He is also editor of the management journal Acta Commercii.

Dr. Maria Bounds (University of Johannesburg, South Africa) Dr Bounds is a lecturer in the Department of Business Management at the University of Johannesburg where she coordinates second-year Business Management modules. Dr Bounds is co-author of Focus on Business Studies and moderator for Business Studies.

Dr. Piotr Buła (Krakow School of Business, Poland) Dr Bula resides in the Department of International Management at Krakow University of Economics (CUE). He is also the Director of the Krakow School of Business. He is a member of the Krakow University of Economics (KUE) Senate and a member of the Economics and International Relations Faculty Council at KUE. Dr Bula is the author of numerous publications in the field of methodology of organisation and management, international management, logistics management, strategic management, risk management, and internal audit. He also serves on the editorial boards of scientific journals.

Dr. Janusz Fudalinski (Krakow University of Economics, Poland) Dr Fudalinski lectures Strategic Management as a member of the Department of Management Strategy and Development of Organizations at Krakow University of Economics. He conducts research specifically in the field of strategic management in no-profit organisations. Dr Fudalinski is the author of numerous publications in and outside of Poland. 
Reproduced with permission of the copyright owner. Further reproduction prohibited without permission. 